\title{
Influence of Long-Term Inhaled Glucocorticoids on the Lung Surfactant Phospholipid Levels in Rats
}

\author{
Oleg A. Rosenberg, MD, PhD, $\mathrm{ScD}^{1^{*}}$; E.S. Lebedeva, $\mathrm{MD}, \mathrm{PhD}^{2}$; L.V. Loshakova; \\ A.Ed. Shulga ${ }^{1}$; A.A. Seiliev, $\mathrm{PhD}^{1}$; V.A. Volchkov, $\mathrm{MD}, \mathrm{PhD}, \mathrm{ScD}^{1}$ \\ ${ }^{1}$ Russian Research Center of Radiology and Surgery Technologies, St. Petersburg, Russia \\ ${ }^{2}$ Pulmonology Research Institute, St. Petersburg, Russia
}

\begin{abstract}
Background: Damage to lung surfactant, which is responsible for the lung local immunity, may contribute to the development of bronchial inflammation in patients with bronchial asthma. Different doses of glucocorticoids produce a stimulating or inhibiting effect on the synthesis of the surfactant protein (SP-A) mRNA. Lung surfactant disorders may negatively influence bronchial homeostasis and aggravate the condition of patients with bronchial asthma and COPD. The objective of this study was to evaluate the influence of long-term inhaled corticosteroids (ICS) on the phospholipid levels of the lung surfactant in rats.

Methods and Results: Inhalations of prednisolone hemisuccinate $(\mathrm{PH})$ were given to white non-pedigree rats weighing 180$200 \mathrm{~g}$ at a dose of $0.3 \mathrm{mg} / \mathrm{kg}$ daily for 30 days. Already by the end of the first study period (10 days), lung surfactant phospholipid levels were found to decrease significantly from $1.35 \pm 0.060 \mathrm{mg}$ to $1.02 \pm 0.045 \mathrm{mg}(P<0.001)$. The decrease was further recorded at Day 20 and Day 30 of the inhalation period: down to $0.94 \pm 0.042 \mathrm{mg}(P<0.001)$ and $1.04 \pm 0.047 \mathrm{mg}(P<0.01)$, respectively. The phospholipid content continued to decrease after termination of inhalations down to $0.80 \pm 0.036 \mathrm{mg}(P<0.001)$ and $0.63 \pm 0.028 \mathrm{mg}$ $(P<0.001)$ at Day 40 and 50 of the experiment. By Day 60 of the experiment (30 days after termination of $\mathrm{PH})$, the phospholipid content in the lung surfactant was restored to the baseline level of $1.29 \pm 0.058 \mathrm{mg}$.

Conclusion: The content of lung surfactant was found to decrease significantly as a result of long-term ICS treatment, which may have a negative effect for chronic lung diseases. (Int J Biomed. 2016;6(3):167-169.).
\end{abstract}

Key Words: inhaled corticosteroids • lung surfactant • COPD • bronchial asthma.

\section{Introduction}

The use of inhaled glucocorticosteroids (also called inhaled corticosteroids or ICS) for bronchial asthma (BA) has significantly decreased the incidence of severe cases and mortality. The use of ICS for COPD also improves the quality of life and decreases the exacerbation rate. However, a small amount of all available ICS is absorbed into the lungs, enters the blood flow and may cause complications of systemic glucocorticoids (GCs). Adverse effects of ICS, such as oral and oropharyngeal candidosis, dysphonia, and cough caused by the irritation of upper airway lead to significant discomfort

*Corresponding author: Prof. Oleg Rosenberg, MD, PhD, ScD. Department of Medical Biotechnology of Russian Research Center of Radiology and Surgery Technologies, St. Petersburg, Russia. E-mail: rozenberg@biosurf.ru in some patients. High doses of ICS (equivalent to $1000 \mu \mathrm{g}$ of fluticasone propionate) are accompanied by complications of systemic GCs, such as pneumonia, glaucoma, cataract, suppression of adrenal function, osteoporosis and diabetes. ${ }^{[1]}$

Many lung diseases, including BA, have been shown to be accompanied by qualitative and quantitative changes in the composition and properties of the lung surfactant. ${ }^{[2,3]}$ The lung surfactant obtained from the lungs of guinea pigs with a model of chronic bronchial asthma has less ability to decrease surface tension, higher content of small aggregates and decreased ratio of saturated phospholipids to surfactant proteins. ${ }^{[4]}$ The influence of long-term ICS therapy on the lung surfactant has been given little attention by the researchers. Short-term use of systemic GCs in pregnant women 48 and 24 hours before delivery causes an increase of lung surfactant synthesis in the fetus; this is standard treatment for prevention of respiratory distress syndrome in newborns. ${ }^{[5]}$ However, a 
stimulating effect on the synthesis of a substance is known to be often replaced by suppression of its synthesis and a decrease in levels of the end product. We assumed that a long-term use of ICS would exhaust the synthesis of the lung surfactant by type II alveolar cells and lead to a decrease of surfactant levels in the lungs.

It should be mentioned here that lung surfactant is a multicomponent natural complex comprising 7 classes of phospholipids, neutral lipids, cholesterol and its esters as well as 4 groups of surfactant proteins having a range of different functions. ${ }^{[2]}$ Lung surfactant enables the breathing mechanism by effectively lowering surface tension at the air/ liquid interface, protects the lungs from physical and chemical effects, has immunomodulating and anti-inflammatory properties, stimulates phagocytosis of alveolar macrophages and mucociliary clearance, and keeps small bronchi open. ${ }^{[2,6,7]}$ That is why a decrease in lung surfactant levels may have negative consequences for the homeostasis of the lung tissue.

The objective of this study was to evaluate the influence of long-term ICS on the phospholipid levels of the lung surfactant in rats.

\section{Methods}

Inhalations of prednisolone hemisuccinate $(\mathrm{PH})$ were given to white non-pedigree rats weighing 180-200 $\mathrm{g}$ at a dose of $0.3 \mathrm{mg} / \mathrm{kg}$ daily for 30 days. The rats had plastic funnels fixed in such a way that their noses and mouths were within the funnel edges. For the inhalations of $\mathrm{PH}$, the ultrasound inhalator Vulkan 1 (Russia) was used for 10 minutes. The dosage was measured by the amount of $\mathrm{PH}$ used during the exposure time. The experiment lasted 60 days: rats received PH daily during the first 30 days, and then they were followed up for another 30 days. Every 10 days 5 rats were sacrificed, and total phospholipid content for both lungs was measured. In this way, rats were studied at Days 10, 20 and 30 (inhalation period) and at Days 40, 50 and 60 (follow-up period). In the control group, rats received inhalations of saline daily during 30 days. Rats were sacrificed in a state of deep thiopental narcosis $(25 \mathrm{mg} / \mathrm{kg})$, in compliance with the NIH Guide for the Care and Use of Laboratory Animals. After their bodies were thoroughly cleared of blood, lungs were extracted along with the trachea and were lavaged 5 times with $5 \mathrm{ml} 36^{\circ} \mathrm{C}$ saline per wash. The lavage was then collected and purified from cells and debris by centrifuging at $1500 \times \mathrm{g},+4^{\circ} \mathrm{C}$ for 10 minutes. The supernatant was then frozen at $-20^{\circ} \mathrm{C}$ for 1 hour and then melted at ambient temperature to form lung surfactant aggregates. The procedure was repeated three times. The resulting suspension was centrifuged at $10000 \times \mathrm{g}$ using a Sigma 6K10 centrifuge (Germany). Lung surfactant residue was resuspended in water, and lipids were extracted using a mixture of organic solvents as suggested by Bligh and Dyer. ${ }^{[8]}$ Neutral lipids were removed by means of cold $\left(-20^{\circ} \mathrm{C}\right)$ acetone and were cleared of any trace of the acetone on a rotary evaporator (RotavaporR-114, Buche, Switzerland) under vacuum. The residue was dissolved in a chloroform and methanol mixture (2:1 ratio by volume). Lung surfactant phospholipid levels were measured by the quantity of nonorganic phosphorus, ${ }^{[9]}$ with the color measured quantitatively at the wavelength $825 \mathrm{~nm}$ on a HitachiU-3400 spectrophotometer (Japan), and phospholipid levels were calculated from the content of nonorganic phosphorus multiplied by 25 (the average ratio of phosphorus in a phospholipid molecule).

Statistical analysis was performed using the statistical software «Statistica» (v6.0, StatSoft, USA). The mean (M) and standard error of the mean (SEM) were calculated. Student's unpaired and paired t-tests were used to compare two groups for data with normal distribution. A probability value of $P<0.05$ was considered statistically significant.

\section{Results}

Figure 1 shows lung surfactant phospholipid levels in the control and treatment groups at specified time points during the period of $\mathrm{PH}$ inhalations and the follow-up period.

The lung surfactant phospholipid content did not differ in lungs of intact rats and of rats receiving saline inhalations amounting to a total of $1.35 \pm 0.060 \mathrm{mg}$ for both lungs (the zero point on Figure 1).

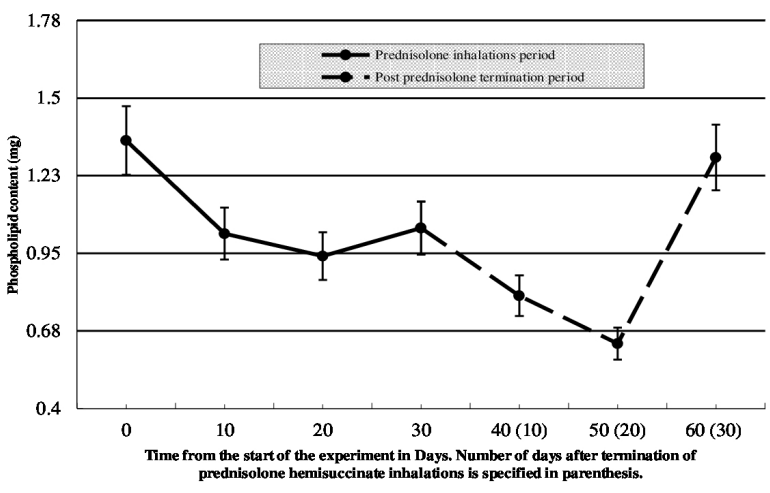

Fig. 1. Dynamics of lung surfactant phospholipid levels during $P H$ inhalations

Inhalations of PH were given to rats at a dose of $0.3 \mathrm{mg} / \mathrm{kg}$ daily for 30 days with a subsequent 30 day follow-up period. Solid line shows the course of PH inhalations, dotted line shows the period after termination of $\mathrm{PH}$. Each point shows the total phospholipid content for both lungs, the average across five animals. The zero point (0) shows the content of phospholipids in control.

Already by the end of the first study period (10 days), lung surfactant phospholipid levels were found to decrease significantly from $1.35 \pm 0.060 \mathrm{mg}$ to $1.02 \pm 0.045 \mathrm{mg}(P<0.001)$. The decrease was further recorded at Day 20 and Day 30 of the inhalation period: down to $0.94 \pm 0.042 \mathrm{mg}(P<0.001)$ and $1.04 \pm 0.047 \mathrm{mg}(P<0.01)$, respectively. The phospholipid content continued to decrease after termination of inhalations down to $0.80 \pm 0.036 \mathrm{mg}(P<0.001)$ and $0.63 \pm 0.028 \mathrm{mg}(P<0.001)$ at Day 40 and 50 of the experiment. By Day 60 of the experiment (30 days after termination of $\mathrm{PH}$ ), the phospholipid content in the lung surfactant was restored to the baseline level of $1.29 \pm 0.058 \mathrm{mg}$. 
A significant decrease in the content of lung surfactant after the 30-day inhalation period with a further restoration after ICS termination is in line with reversible suppression of surfactant protein SP-A ( $A_{1}$ and $\left.A_{2}\right)$ gene expression by dexamethasone. ${ }^{[10]}$ The study has shown that low doses of dexamethasone $(10 \mathrm{nM})$ increase the synthesis of the SP-A mRNA in human fetus lung tissue explants and that high doses $(100 \mathrm{nM})$ suppress it. ${ }^{[10]}$ In a different model, involving pulmonary adenocarcinoma cell line NCI-H441, dexamethasone suppressed the synthesis of the SP-A mRNA and SP-A levels even at a low dose $(10 \mathrm{nM})$. At the higher dose of $100 \mathrm{nM}$, dexamethasone suppressed the content of SP-A down to $10 \%$ of the baseline, the degree of suppression depending both on the dose of dexamethosone and on the time of the cell exposure to GCs. This effect of inhibition of SP-A gene expression was reversible and mediated through the corticosteroid receptor. ${ }^{[11]}$

\section{Discussion}

The discovered significant decrease of surfactant levels in the rat lungs as a result of 30-day course of PH can help to explain the pathogenesis of complications caused by longterm ICS used for treatment of such chronic lung diseases as BA and COPD. Long-term ICSs are known to double the risk of severe pneumonias in COPD patients. ${ }^{[12]}$ Severe pneumonias have been shown to have lung surfactant deficit, and surfactant replacement therapy is used successfully for these conditions. ${ }^{[13,14]}$ Lung surfactant system impairment may be the cause of bronchial obstruction, mucosal edema and increased liquid secretion into the bronchi. ${ }^{[3]}$ In this way, already existing impairments of the lung surfactant system in BA patients may be aggravated by additional suppression of its synthesis due to ICS. It should be mentioned that intratracheal administration of liposomes from egg lecithin and cholesterol to rats, ${ }^{[15]}$ or multiple administration of lung surfactant to newborns, increases the synthesis of endogenous surfactant, ${ }^{[16]}$ which is associated with reutilization of $80 \%$ of surfactant phospholipids when surfactant is synthesized de novo. We may suppose that inhalations of natural formulations of lung surfactant will stimulate the synthesis of endogenous surfactant and weaken dependency on ICS in BA patients.

\section{Acknowledgements}

We thank Natalia Zvonareva and Evgenia Zvonareva for writing assistance and translation of the manuscript into English.

\section{Competing interests}

The authors declare that they have no competing interests.

\section{References}

1. Kelly HW, Nelson HS. Potential adverse effects of the inhaled corticosteroids. J Allergy Clin Immunol. 2003; 112(3):469-78.

2. Rosenberg O, Seiliev A, Zhuikov A. Lung surfactant: correlation between biophysical characteristics, composition, and therapeutic efficacy. In: Gregoriadis G., editor. Liposome Technology. New York: Informa Healthcare; 2006:317-345.

3. Hohlfeld JM. The role of surfactant in asthma. Respir Res. 2002; 3(1):4. doi:10.1186/rr176.

4. Cheng G, Ueda T, Sugiyama K, Toda M, Fukuda T. Compositional and functional changes of pulmonary surfactant in a guinea-pig model of chronic asthma. Respir Med. 2001; 95(3):180-6.

5. Mwansa-Kambafwile J, Cousens S, Hansen T, Lawn JE. Antenatal steroids in preterm labour for the prevention of neonatal deaths due to complications of preterm birth. Int $\mathrm{J}$ Epidemiol. 2010; 39 (Suppl 1):i122-33.

6. Volchkov V, Dubrovskaya V, Danilov L, Rosenberg O. Modification of X-ray alveolitis in rat lungs by intratracheal administration of phosphatidylcholine-cholesterol liposomes. Eur Respir J. 2002; 20 (Suppl 38):486s.

7. Floros J, Phelps DS, Pison U, Spragg R. Pulmonary surfactant-update on function, molecular biology and clinical implications. Curr Respir Med Rev. 2005; 1(1):77-84.

8. Bligh EG, Dyer WJ. A rapid method of total lipid extraction and purification. Can J of Biochem Physiol. 1959; 37(8):911-7.

9. Vaskovsky VE, Kostetsky EY. A universal reagent for phospholipid analysis. J Chromatogr. 1975; 114 (1):129-41.

10. Hoover RR, Floros J. SP-A 3'-UTR is involved in the glucocorticoid inhibition of human SP-A gene expression. Am J Physiol. 1999; 276(6 Pt 1):L917-24.

11. Liley HG, White RT, Benson BJ, Ballard PL. Glucocorticoids both stimulate and inhibit production of pulmonary surfactant protein A in fetal human lung. Proc Natl Acad Sci USA. 1988; 85(23):9096-100.

12. Suissa S, Patenaude V, Lapi F, Ernst P. Inhaled corticosteroids in COPD and the risk of serious pneumonia. Thorax. 2013; 68(11):1029-36.

13. Rozenberg OA. Pulmonary Surfactants for Acute and Chronic Lung Diseases (Part II). Gen Reanimatol. 2014; 10(5):69-86.

14. Rosenberg O, Alekseev A, Iakovlev A, Shvechkova M, Seiliev A, Volchkov V. Surfactant therapy of A/H1N1 severe pneumonia and ARDS is a chance for survival. Eur Respir J. 2010; 56 (Suppl 54): 772.

15. Rosenberg OA, Kirillov YA, Danilov LN, Loshakova LV, Lebedeva ES, Shylga AE, Ses TP. The lung surfactant immune system response to intratracheal administration of "empty" liposomes. J Liposome Research. 1994; 4(1):203-212.

16. Soll R, Ozek E. Multiple versus single doses of exogenous surfactant for the prevention or treatment of neonatal respiratory distress syndrome. Cochrane Database Syst Rev. 2009; 1: CD000141. doi: 10.1002/14651858 